Nunt. Antiquus, Belo Horizonte, v. 14, n. 1, p. 207-232, 2018

\title{
Euristeu, drama satírico de Eurípides
}

\section{Eurystheus, a Satyr Play by Euripides}

\author{
Wilson Alves Ribeiro Jr. \\ Universidade de São Paulo, São Paulo, São Paulo / Brasil \\ epwidos@gmail.com
}

Resumo: O drama satírico Euristeu, de Eurípides, de data desconhecida e com certeza identificado com o décimo segundo trabalho de Héracles, chegou até nossos dias em estado fragmentário e seu enredo é, até o momento, altamente conjetural. O objetivo deste artigo é, em primeiro lugar, apresentar uma tradução portuguesa dos fragmentos conhecidos e dos fragmentos incertamente atribuídos ao drama, com breves comentários e, em segundo lugar, examinar a posição desses fragmentos no enredo dramático, a partir de elementos míticos disponíveis em fontes literárias e iconográficas anteriores a 400 a.C.

Palavras-chave: Eurípides; Héracles; Euristeu; drama satírico; teatro grego; fragmentos.

Abstract: Eurystheus, an Euripidean satyr play of unknown date identified with certainty with the Twelfth Labor of Heracles, reached us in a fragmentary state, and its plot is so far highly conjectural. The purpose of this article is, at first, to present a Portuguese translation of both the certain and the uncertain fragments attributed to Eurystheus, with brief commentaries; and secondly, to discuss the position of these fragments within the drama in the light of mythical elements available from literary and iconographic sources prior to $400 \mathrm{BCE}$.

Keywords: Euripides; Heracles; Eurystheus; satyr play; Greek Theater; fragments.

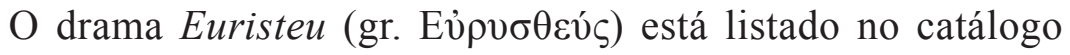
das obras de Eurípides, ${ }^{1}$ e sua natureza satírica foi atestada por dois

\footnotetext{
${ }^{1}$ Os dramas de Eurípides são mencionados pelo título completo; abreviaturas de autores e obras da Antiguidade seguem o Oxford Classical Dictionary e, no caso de omissão, o Greek-English Lexicon, de Liddel-Scott-Jones; os documentos iconográficos são
} 
comentadores tardios, Pólux e Estêvão de Bizâncio. ${ }^{2}$ Não há nenhuma hipótese disponível, nenhum documento iconográfico, e a data da primeira apresentação é desconhecida. Os exíguos fragmentos atribuídos ao drama se ajustam razoavelmente à participação de Euristeu no mito do $12^{\circ}$ Trabalho de Héracles, o que permitiu a reconstrução aproximada do enredo. O fragmento trágico adesp. 658, que tem algumas relações com o Euristeu, será apresentado e comentado à parte.

\section{0 mito do $12^{\circ}$ trabalho de Héracles ${ }^{3}$}

Estênelo, pai de Euristeu, era primo irmão de Alcmena, mãe de Héracles, e consequentemente Euristeu era primo em segundo grau do herói. Hera enganou Zeus, divino pai de Héracles, ao apressar o parto da mãe de Euristeu e fazê-lo nascer um pouco antes, ${ }^{4}$ para que Euristeu reinasse em Argos e Héracles ficasse subordinado a ele. Os mitógrafos antigos não explicam, porém, a razão específica de Héracles ter realizado

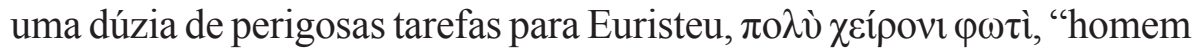
muito inferior" a ele (Od. 622). Eurípides menciona a possibilidade de Hera ter instigado um compromisso entre Euristeu e Héracles que possibilitaria a volta do herói e seus familiares a Argos (Héracles 17-21), mas também aventa a possibilidade de se tratar de simples afronta ou

referidos pelo nome da cidade (ou museu) onde estão conservados e pelo número de inventário. Abreviatura bibliográfica: TrGF 5.1 e 5.2 = Kannicht (2004); TrGF 2 = Kannicht e Snell (2007). As aspas angulares « » assinalam a posição dos fragmentos nas citações; nos comentários, o negrito assinala, à guisa de subtítulo, os trechos da tradução comentados logo a seguir.

${ }^{2}$ Título: IG XIV 1152 col. I 24 e IG II/III2 2363 col. II 51 (TrGF 5.1, p. 57-61). Pólux e Estêvão de Bizâncio conservaram, respectivamente, os F 373 e 380.

${ }^{3}$ Fontes literárias relevantes, até 400 a.C.: Il. 8.366-9, 15.639-40 e 19.95-133; Od. 11.6236, Hes. Theog. 310-12 e 769-73; h. Hom. 15; Pind. F 249a-b; Bacch. 5.56-92; Panyas. F 17; Soph. Trach. 1097-9; Eur. Héracles 17-21; 425-35; 611-2; 619-21; 1169-70; 1275-8. Após 400 a.C.: Apollod. Bibl. 2.5.12-2.5.1; 2.5.12; Paus. 3.25.4-5; Strab. 8.5.1; e Diod. Sic. 4.25-26. A iconografia da descida de Héracles ao Hades é relativamente numerosa; as principais imagens são Louvre E701 e F204, Moscou 70, Munique 1493, Olímpia B2198, Villa Giulia 50649, Vaticano 372 (ver Ogden, 2013, p. 110-114).

${ }^{4}$ Sobre o engano de Hera contra Zeus, ver Ribeiro Jr. (2011, p. 41-43). 
crueldade (Heráclidas 953). A conhecida história da penalidade imposta a Héracles pelo Oráculo de Delfos depois da morte da esposa e dos filhos ${ }^{5}$ foi contada por [Apolodoro] (Bibl. 2.4.12-2.5.1) muitos séculos depois da Ilíada, mas pode certamente refletir tradições anteriores (GANTZ, 1993, p. 382) sobre a necessidade de Héracles cumprir as perigosas ordens de Euristeu (h. Hom. 15.4-5). O poeta Paniassis (F 2) menciona a ida de Héracles ao Oráculo de Delfos, mas não dá nenhum detalhe sobre a finalidade da visita, pelo menos no curto fragmento que chegou até nós.

A descida de Héracles ao Hades ${ }^{6}$ e a captura do monstruoso Cérbero era façanha conhecida do poeta da Ilíada, dos antigos pintores de vasos e de Píndaro, Baquílides, Eurípides e Sófocles, entre outros. Hesíodo diz que Cérbero tinha cinquenta cabeças, e Píndaro, cem (F 249b.1); as demais fontes, muito mais moderadas, dão conta de apenas uma (Fig. 1), duas (e.g. Munique 1493) ou três (Sófocles, Eurípides, Louvre E701, Villa Giulia 50649, etc.).

FIGURA 1 - Héracles conversa com Perséfone. Cena de cótila ou esquifo coríntio de figuras negras, hoje perdido. Argos, c. 590-575 a.C.

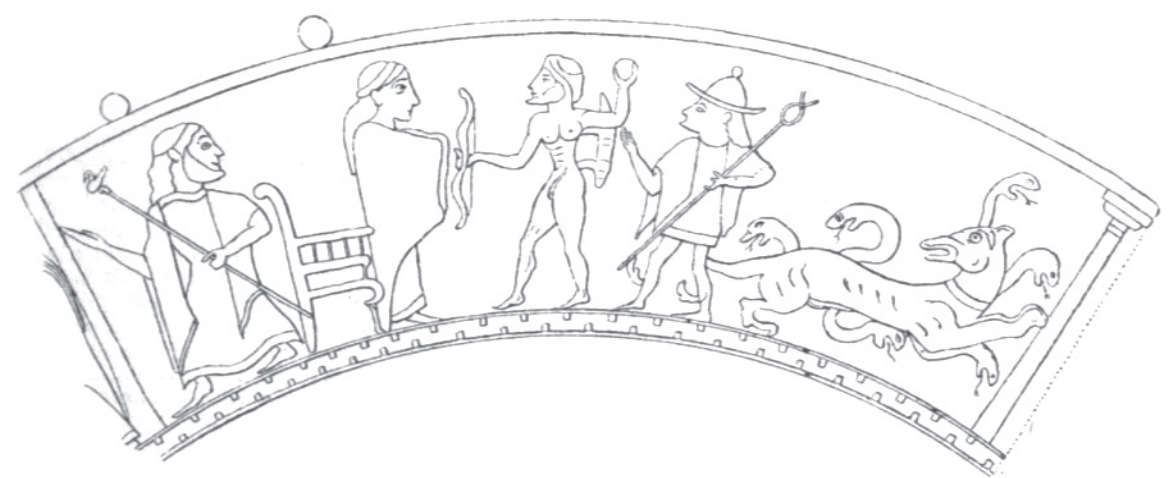

Fonte: ROSCHER, 1884-1937 (s.v. Kerberos) ${ }^{7}$, domínio público.

\footnotetext{
${ }^{5}$ Em memorável episódio do Héracles (922-1015), o herói mata a esposa e os próprios filhos diante de Anfitrião, seu pai terreno, durante acesso de loucura. A história é, no entanto, muito mais antiga do que a tragédia de Eurípides (cf. Cypr. arg. 4, Stesich. F 230, Pherec. F 17, Panyas. F 1).

${ }^{6}$ Sobre a ida de mortais ao Hades, ou catábase, ver Bostock (2007, p. 12-18).

${ }^{7}$ Originalmente publicado em Archäologische Zeitung, v. 15, 1859, tafel cxxv.
} 
Na época do Héracles, de Eurípides, outros detalhes da apreensão de Cérbero eram já conhecidos. Héracles adentrou o Hades por uma caverna do Cabo Tênaro ${ }^{8}$ (Héracles 23-25), depois de participar dos sagrados mistérios (613), ${ }^{9}$ encontrou-se com a sombra de Meleagro e com Teseu e Pirítoo, ambos ainda vivos, e conseguiu salvar seu amigo Teseu. ${ }^{10}$ A captura de Cérbero pode ter ocorrido à força $(612-3)^{11}$ ou mediante entendimento entre Héracles, Perséfone e Hades, como sugerem algumas cenas de vasos datados do século VI a.C. em diante (e.g. Moscou 70, Vaticano 372 e Louvre F204). A mais antiga representação do encontro entre Héracles e Cérbero no Hades, do início do século VI a.C., é um tanto dúbia a esse respeito (Fig. 1). No centro, vemos Héracles diante de Perséfone e seu trono, ${ }^{12}$ com o arco e uma pedra nas mãos; à esquerda do trono, Hades está fugindo; Hermes, logo atrás de Héracles, ergue o braço direito (em saudação?); e Cérbero, com apenas uma cabeça e serpentes saindo do corpo, tenta escapar pela direita. Podemos imaginar, aqui, uma típica discussão em família, pois Hades é irmão de Zeus, e os outros deuses, filhos de Zeus com diferentes mães. ${ }^{13} \mathrm{O}$ sucesso de Héracles nessa empreitada foi registrado pelos decoradores de vasos no

${ }^{8} \mathrm{O}$ cabo Tênaro é um promontório situado no extremo sul do Peloponeso, no território da Lacônia. Sobre essa entrada do Hades, ver também Apollod. Bibl. 2.5.12 e Paus. 3.25.5. Xenofonte (An. 6.2.2) conservou uma versão alternativa: Héracles teria descido ao Hades em local situado no promontório Arquerusiano (atual Cabo Baba), próximo de Heracleia Pontica, pólis fundada pelos gregos c. 560 a.C. no noroeste da Turquia moderna. O nome Heracleia foi escolhido justamente pelo fato de acreditarem que Héracles entrou no Hades por ali.

${ }^{9}$ Os mistérios de Elêusis. Ver também Apollod. Bibl. 2.5.12 e Diod. Sic. 4.25.1.

${ }^{10}$ Ver seção 3, infra.

${ }^{11}$ Os dados literários e iconográficos disponíveis não permitem relacionar, de forma conclusiva, a controvertida história de Héracles ter ferido Hades $\dot{\varepsilon} v$ Пú $\lambda \omega$, "em Pilos" (Il. 5.395-7; Panyas. F 26; Pind. Ol. 9.29-35), ou غ̇v $\pi u ́ \lambda \eta ̣$, "nos portões [do Hades]", durante o episódio da captura de Cérbero. Ver Gantz (1993, p. 70-71 e 414-416) e Bostock (2007, p. 13-14).

${ }^{12}$ A probabilidade de se tratar da deusa Atena é remota (cf. Il. 8.364-9; Od. 11.623-6); ver Gantz (1993, p. 413), Schefold e Giuliani (1978, p. 129).

${ }^{13}$ Perséfone é filha de Deméter (Od. 11.217); Hermes, de Maia (Hes. Theog. 938-9); e Héracles, de Alcmena (Il. 14.323-4). 
final desse mesmo século, em cenas que mostram Euristeu escondido dentro de um grande jarro quando Héracles chega ao palácio real para entregar a encomenda (Louvre E701, Villa Giulia 50649).

$\mathrm{Na}$ Biblioteca de [Apolodoro], a mais completa das fontes posteriores a Eurípides, a captura de Cérbero é o último Trabalho que o herói realizou por ordem de Euristeu. $\mathrm{O}$ mitógrafo acrescenta vários detalhes às antigas histórias, a maioria de pouca relevância para o estudo do Euristeu; além da já mencionada penalidade imposta pelo Oráculo de Delfos, destaco apenas outra informação: Héracles levou Cérbero de volta ao Hades depois de mostrá-lo a Euristeu, o que muito provavelmente constituiu a parte final do acordo entre ele e Perséfone. Pausânias e Estrabon confirmam, finalmente, que Héracles trouxe Cérbero através da caverna do Cabo Tênaro.

O mito inspirou o poema Cérbero, de Estesícoro; os dramas satíricos Euristeu, de Eurípides, Cérbero e Sátiros no Tênaro, de Sófocles, e talvez um quarto, o Héracles de Sófocles; o drama Pirítoo, atribuído a Crítias ou a Eurípides; e um outro Pirítoo, de autor anônimo do século IV a.C. Do poema de Estesícoro temos apenas o título (Poll. Onom. 10.52) e, dos demais, escassos fragmentos.

\section{Fragmentos do drama satírico Euristeu $^{14}$}

Há dez fragmentos confirmados (F 371-80) e mais dois de atribuição incerta ( $\mathrm{F} * 863, \mathrm{~F} * 936)$, além do $\mathrm{F}$ trag. adesp. 658. Com exceção desse último, inscrito em dois papiros, todos vêm de fontes secundárias: Erotiano, Pólux, Estobeu, Ateneu, Estêvão de Bizâncio, Eliano, Luciano, um escólio da Hécuba e o léxico compilado por Andrea Lopadiota no século XIV (GUIDA, 1979).

F 371

$\operatorname{HPAK} \Lambda \mathrm{H} \Sigma$

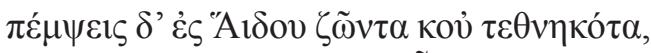

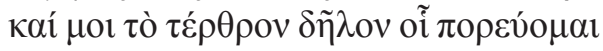


Pechstein (1998, p. 145-76), Van Looy (2002, p. 133-141), Collard e Cropp (2008, v. 1, p. 403-11), O’Sullivan e Collard (2013, p. 392-7).
} 


\section{HÉRACLES}

Enviarás ao Hades um homem vivo, não morto, e para mim está claro o término do caminho que sigo.

F 371 = Erot. p. 126.14-17. Citação direta da passagem, com

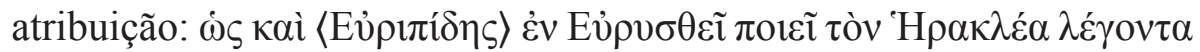


Euristeu, faz Héracles falar assim: «F 371»". Enviarás ao Hades um homem vivo. Não há dúvidas quanto à atribuição do fragmento a Héracles, que com certeza se dirige a Euristeu; há nítido paralelo entre

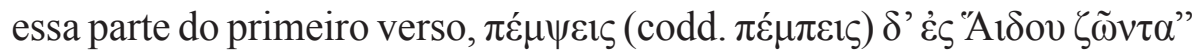
e Heráclidas 949, quando Alcmena invectiva Euristeu após a derrota do


que ele descesse ao Hades ainda vivo".

F 372

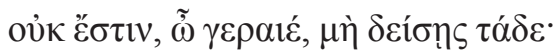

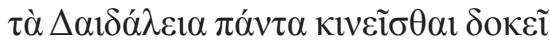

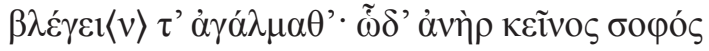

Não são reais, meu velho, não tenha medo delas; todas as estátuas de Dédalo parecem se mover e olhar, tão engenhoso é aquele homem.

F $372=$ Schol. ${ }^{\mathrm{MB}}$ Eur. Hécuba 838. Contexto: esclarecimento do escoliasta sobre uma parte (836-840) de longa súplica de Hécuba, dirigida a Agamêmnon e que contém a expressão $\Delta \alpha \iota \delta \alpha ́ \lambda$ ov $\tau \dot{\chi} \chi v \alpha ı \sigma ı v$,

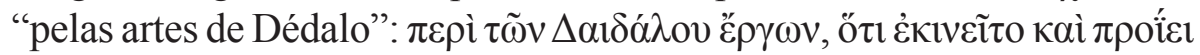

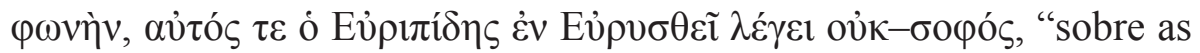
obras de Dédalo, que se moviam e pareciam falar, o mesmo diz Eurípides no Euristeu, «F 372»". Meu velho. Héracles provavelmente se dirige a


mais coloquial, por "ô velho". No Ciclope 145, Odisseu se dirige a Sileno de forma semelhante: [...] $\dot{\omega} \varsigma$ óă $\varsigma, \gamma \varepsilon \dot{\rho} \rho o v$, "como vês, meu velho". As estátuas de Dédalo. O legendário Dédalo era, para os gregos, misto de artista, artesão e inventor de épocas remotas a quem eram atribuídas técnicas, inovações e utensílios cuja origem se perdera no tempo (e.g. 
Pl. Hp. mai. 282a). De certo modo, Dédalo era o equivalente do divino artífice, Hefesto, na esfera humana. Seu nome, $\Delta \alpha i \delta \alpha \lambda$ os, significa 'trabalhador astucioso/habilidoso'; o adjetivo $\delta \alpha i \delta \alpha \lambda o \varsigma$, 'trabalhado com habilidade/arte/refinamento' (e.g. Héracles 471); e o verbo cognato $\delta \alpha 1 \delta \alpha \dot{\alpha} \lambda \omega \omega$, 'trabalhar habilidosamente/com refinamento' (e.g. Hécuba 470). Dizia-se que as esculturas criadas por Dédalo ( $\tau \alpha \dot{\alpha} \delta \alpha i ́ \delta \alpha \lambda \alpha$, Paus.

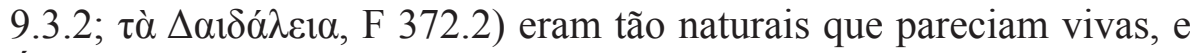
Ésquilo, no drama satírico Sagrada delegação ou Competidores dos Jogos Ístmicos, afirma que a elas só faltava voz (F 78a.6-7). Há vários mitos sobre Dédalo; o mais conhecido é o da sua associação com o rei Minos, de Creta, para quem construiu o labirinto que continha o Minotauro (Il. 18.590-2). Dédalo aparece em um ou mais dramas de Sófocles: Dédalo (F 159-64a), tragédia ou drama satírico, talvez outro título para Homens de Camicos (F 323-7), e mais dois fragmentos incertos (F 992 e 1030). Eurípides mencionou ou explorou as tradições sobre Dédalo no Euristeu e nas tragédias Hécuba (836-8), Os cretenses (F 968) e, talvez, no Teseu (F 390). E a habilidade de Dédalo, assim como a naturalidade de suas esculturas, foram também exploradas pelos poetas cômicos: Aristófanes (Dédalo, F 191-204), Cratino (Trácias, F 75) e, talvez, Platão Cômico (F 293). Engenhoso. O sentido de бopós, aqui, é de engenhosidade e capacidade artesanal. No caso específico de Dédalo, essa qualidade levou Minos a raptá-lo e escravizá-lo (Xen. Mem. 4.2.33); em outras tradições, porém, Dédalo fugiu de Atenas para Creta a fim de escapar de acusação ou condenação por homicídio (Apollod. Bibl. 3.15.8; Diod. Sic. 4.76.4-7).

\section{F 373}

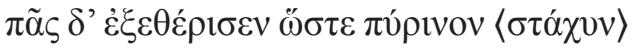

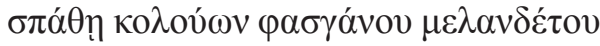

E todos (as) ceifaram, como se corta espiga de trigo, com a lâmina da espada de negros engastes.

F 373 = Poll. Onom. 10.145. Contexto: citação direta, غ̇v




'ceifar completamente', 'acabar de ceifar'. Na tradução do verso, 
muito corrompido e com diversas reconstruções conjeturais, segui aproximadamente a recomendação de O'Sullivan e Collard (2013, p. 395 ad loc.). O sujeito "todos" abrange, certamente, Sileno e os sátiros; provavelmente é Sileno quem conta a história. Espada de negros

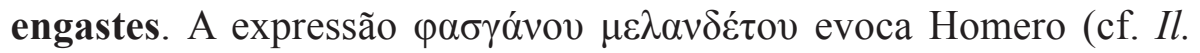

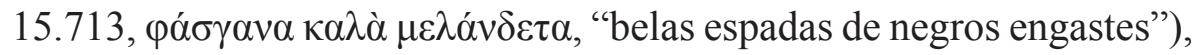
o que confere ares épicos ao relato.

F 374

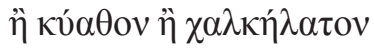



aplicando um cíato ou uma

concha de bronze nestes meus olhos pisados.

F 374 = Poll. Onom. 10.108. Contexto: citação direta, $\sigma \kappa \varepsilon v ̃ o \varsigma$

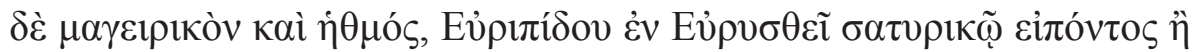


disse Eurípides no drama satírico Euristeu, «F 374»”. Concha de bronze. $\mathrm{O} \dot{\eta} \theta \mu$ ó $\varsigma$ era uma espécie de peneira de metal ou concha perfurada, colocada no topo de vasos para coar ou filtrar o vinho, ${ }^{15}$ também utilizada para tratar contusões - especialmente olhos pisados - por ser de metal e fria (Arist. [Pr.] 890b.7). Olhos pisados. Os poetas cômicos contemporâneos de Eurípides recorriam amiúde à imagem do vं 'olho preto/pisado' e de outras contusões presentes ou futuras em suas comédias (e.g. Ar. Ach. 551, Pax 541-2 com schol. ad loc., Lys. 444 e Vesp. 1386; Plato Com. F 192). Apolofanes ${ }^{16}$ (F 3) utilizou expressão muito parecida com a do fragmento de Eurípides: \langle\rangle$\kappa v ́ \alpha \theta$ ov $\lambda \alpha ́ \beta$ vं$\omega \pi_{i}$ ors, "[...] eu pegaria um cíato para meus olhos pisados”.

F 375

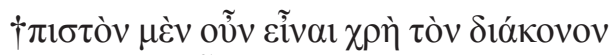

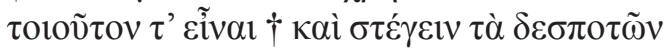

\footnotetext{
${ }^{15}$ Ver exemplos em Reger (2012, p. 156-7).

${ }^{16}$ Poeta associado à Comédia Antiga, fl. 400-380 a.C. Dele restam apenas alguns fragmentos.
} 
†confiável precisa ser, realmente, o servo;

e ser assim $\uparrow$ também, manter em segredo os assuntos dos mestres.

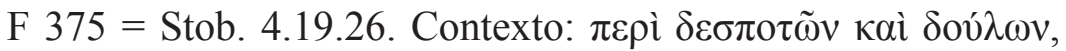

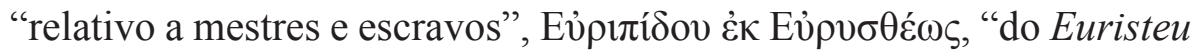
de Eurípides". Passagem corrompida nos manuscritos, parcialmente reconstruída pelos especialistas, ainda muito controvertida. É possível que se trate de fala de Sileno ou dos próprios sátiros, uma vez que eles frequentemente falam de si mesmos como escravos de alguém (e.g. Ciclope 31; 76-81).

\section{F 376}



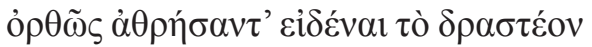

não sei por qual medida a fortuna dos mortais deve ser corretamente observada, para saber o que precisa ser feito.

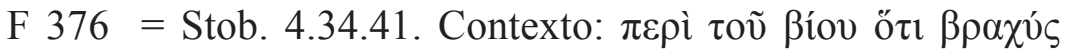
[...]: Eủ [...]: do Euristeu de Eurípides. «F 376»”. As incertezas da fortuna e sua influência na vida humana, lugar-comum entre os autores gregos antigos, são frequentemente mencionadas pelos poetas trágicos. Note-se que a mais antiga referência conhecida é a dos v. 928-9 do Agamênon de Ésquilo, duas ou três décadas anterior ao conhecido relato de Heródoto sobre o encontro entre Sólon e Creso (1.32), posteriormente comentado e analisado por Aristóteles na Ética a Nicômaco (1099b-1100a). ${ }^{17}$ Menções ao tema em outros poetas trágicos: Sófocles, OT 1529-30, Trach. 1-3, F 590-3 e 646; Eurípides, Heráclidas 865-6, Andrômaca 100-103, Troianas 509-10, Ifigênia em Áulis 161-3; e Dionísio de Siracusa, ${ }^{18}$ F 3.

${ }^{17} \mathrm{O}$ Agamêmnon de Ésquilo é de 458 a.C. e as Histórias de Heródoto, de 430-425 a.C. (partes dessa extensa obra podem, no entanto, ter sido divulgadas pelo autor alguns anos antes).

${ }^{18}$ Dionísio I (ou Dionísio, o Antigo), tirano de Siracusa de 405 a 367 a.C., frequente alvo de pilhérias por suas pretensões de escrever poesia trágica. Pouco antes de sua morte, no entanto, venceu as Leneias de 367 a.C., o que não é pouca coisa. 


\section{F 377}



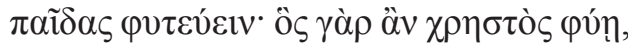

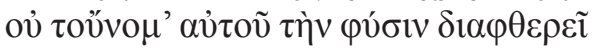

é fútil mortais evitarem filhos bastardos ao engendrar filhos; ele se tornará virtuoso, pois esse termo não corromperá a natureza dele.


$\pi \alpha i \tilde{\delta} \alpha \varsigma)$. Eủ

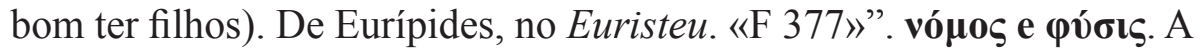
oposição entre a natureza ( $\varphi v ́ \sigma ı)$ ) e rótulos/convenções determinados por costumes, leis e outros elementos culturais (vó o $_{\text {) }}$ era muito debatida na época de Eurípides (ver Guthrie, 1991, p. 57-126). O poeta mencionou a predominância dos impulsos naturais sobre as convenções sociais na Auge (F 265a), o equilíbrio entre ambos no Íon (642-4) e defendeu a

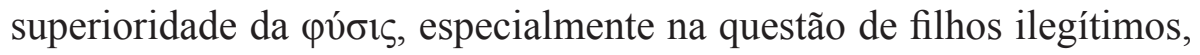
na Andrômaca (638), na Andrômeda (F 141), na Antígona (F 168) e no Euristeu. Para Eurípides, os filhos bastardos são adequados por sua própria natureza, em contraposição aos rótulos e estatutos sociais da época, que depreciavam filhos nascidos fora do casamento, especialmente se as mães não eram do mesmo nível social dos pais.

\section{F $378^{19}$}

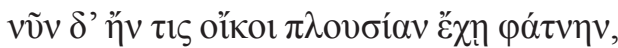

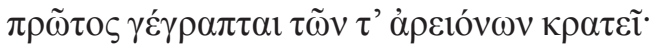



atualmente, se alguém mantém farta mesa na sua casa, inscrevem-no como o primeiro e ultrapassa os melhores do que ele;

e observamos suas ações menos do que suas riquezas.

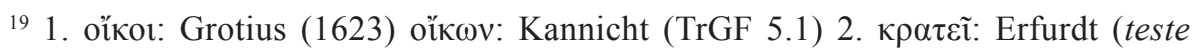

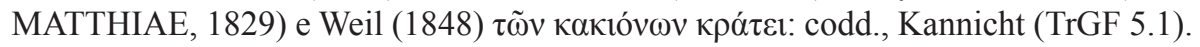


F $378=$ Stob. 4.31.42. Contexto: ( $\pi \varepsilon \rho i ̀ ~ \pi \lambda$ ov́

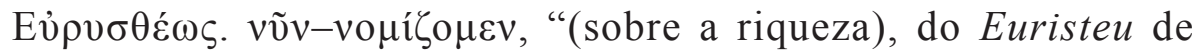
Eurípides. «F 378»". Passagem de difícil tradução, sem muito sentido nos manuscritos; diversos especialistas propuseram correções, como de praxe, e adotei basicamente as lições aceitas por Van Looy (2002, p. 140; ver outras opções no aparato da nota 19). O trecho, com as modificações, parece dizer que pessoas inferiores e ricas são avaliadas por suas riquezas, têm mais prestígio do que as pessoas superiores a elas e deixam de ser levadas em conta por suas ações. Aparentemente, alguém falava de Euristeu... ou trata-se apenas de comentário sobre a importância da comida.

\section{F 379}

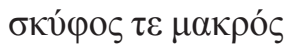

e um esquifo enorme.

F 379 =Ateneu 11.99.35. Contexto: sobre os gêneros masculino e




masculino: «F 379»".

\section{$379 a^{20}$}

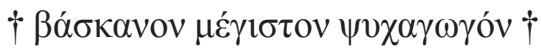

um feiticeiro, um grande condutor de almas.

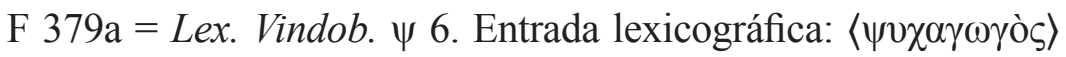

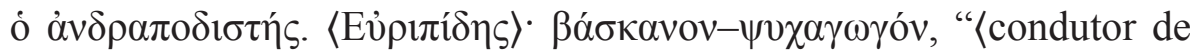


está irreparavelmente corrompida, consequentemente é de tradução difícil (O'Sullivan e Collard, 2013, p. 396 ad loc.). O sentido preciso da passagem foi discutido por Wilamowitz, Mette, Pechstein, Steffen e outros (ver Kannicht, TrGF 5.1 ad loc. e Van Looy, 2002, p. 140, n. 12). Condutor de almas. O $\psi v \chi \alpha \gamma \omega \gamma o ́ \varsigma$ é um condutor de almas, alguém que conjura almas do Hades para questioná-las. Ésquilo recorreu a essa palavra no título de

\footnotetext{
${ }^{20}$ Óbelos adicionados por Collard e Cropp (2008, ad loc.).
} 


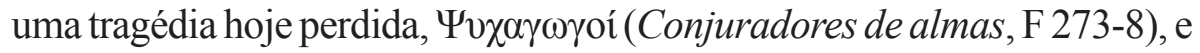
para se referir, em Persas 687, à invocação do espectro do rei persa Dario. Sófocles, no único fragmento do seu drama satírico Cérbero (F 327a),

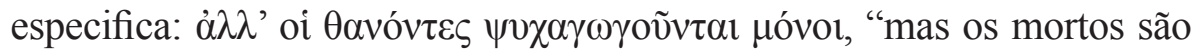
os únicos cuja almas são conduzidas”. Em Alceste 1128, Eurípides faz


e que trouxe Alceste de volta, não o espectro dela.

F 380



do Tártaro.

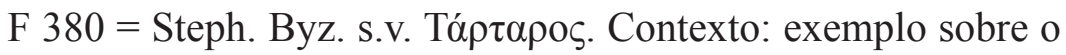

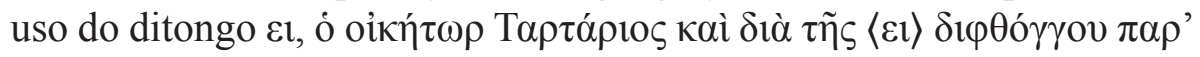
Eủ lugar do ditongo eı, de acordo com Eurípides no drama satírico Euristeu”. Estevão de Bizâncio, que viveu no século VI, provavelmente se baseou no texto Пepì ỏ $\rho$ o $\gamma \rho \alpha \varphi$ ías, Da ortografia, do gramático Élio Herodiano (século II); na p. 588.4 desse tratado há uma entrada idêntica. O Tártaro era, originalmente, a região situada na parte mais inferior e mais remota do universo grego (e.g. Il. 8.13-6), onde estavam aprisionados os titãs derrotados por Zeus. Ficava bem abaixo do Hades (e.g. Il. 8.477-81 e 14.278-9; Hes. Theog. 717-33) e, depois de algum tempo, passou a se identificar com o próprio Hades (e.g. Hes. Sc. 254-5). Aqui, alguém mencionou o Hades e, talvez, o próprio Cérbero (TrGF 5.1 ad loc.), se levarmos em conta o contexto do fragmento.

\section{$\mathrm{F} * 863$}

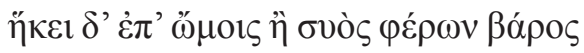



ele voltou carregando nos ombros um pesado javali, ou um lince disforme, fera que nasceu com dificuldade.

$\mathrm{F} * 863=$ Ael. $N A$ 14.6. Contexto: sobre a natureza e ferocidade

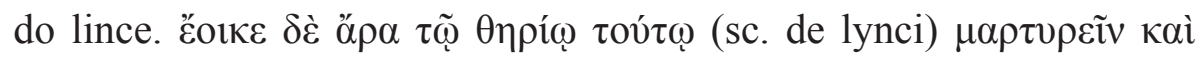




também Eurípides testemunha a falta de beleza dessa fera (sc. do lince), quando diz em algum lugar $« \mathrm{~F} * 863 » "$. Fera que nasceu com

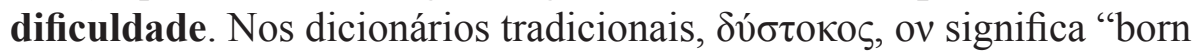
for mischief” (LIDDELL-SCOTT-JONES, 1996), i.e. "nascido para causar dano" ou "enfanté pour le malheur, funeste" (BAILLY, 1963), i.e. "nascido para a infelicidade, funesto", Van Looy (2002) acompanhou


le mal", i.e. "fera funesta e nascida para o mal". Collard e Cropp (2008, v. 2, p. 483, ad loc. nota 1), por outro lado, preferiram a tradução "that gives birth with difficulty", i.e. "que dá à luz com dificuldade", possibilidade aventada pelo Diccionario Griego-Español (ADRADOS; SOMOLINOS, 2003). Considerando que o prefixo $\delta v \sigma-$ marca ideias de dificuldade ou infelicidade e que o radical ๘око- está ligado ao ato de dar à luz, ${ }^{21}$ optei pela segunda interpretação. Creio que, a despeito do

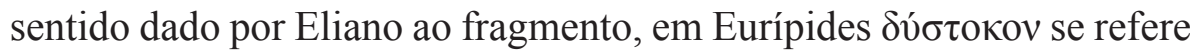
ao tamanho da fera: era tão grande que a mãe pariu com dificuldade. Eliano só conta que a passagem é de Eurípides, mas não se recorda ou não julgou necessário precisar de qual obra. Estudiosos antigos, como Hartung e Wagner, atribuíram o fragmento ao Euristeu (TrGF 5.1 ad loc.), e, mais recentemente, Goins (1989) voltou a defender essa possibilidade; inclino-me a concordar com ele. Outras atribuições: Filoctetes e Sileu.

\section{F $* 936$}

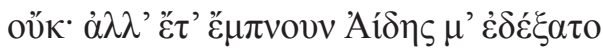

Não, eu ainda respirava quando Hades me recebeu.

F *936 = Luc. Nec. 1.12. Contexto: Menipo volta do Hades, encontra-se com um amigo e fala sobre a viagem. $\mathrm{O}$ amigo pergunta:

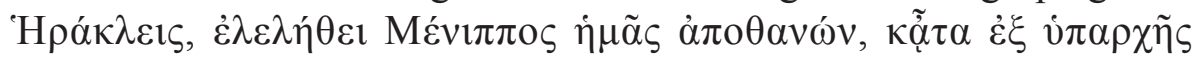
à $\alpha \beta \varepsilon \beta i ́ \omega \kappa \varepsilon v$; " $"$ por Héracles, será que nos escapou que Menipo foi morto e, agora, está vivo de novo?", e a resposta de Menipo é justamente o F *936. No início desse diálogo, alternativamente intitulado Menipo ou

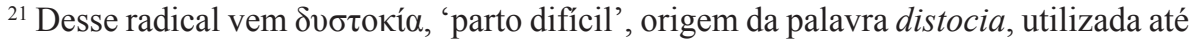
hoje na Medicina.
} 
Necromancia, Luciano parodia duas passagens de Eurípides, Héracles 523-4 (=Nec. 1.1-2) e Hécuba 1-2 (=Nec. 9-10), citadas ao pé da letra; pouco depois, na linha 12 dos manuscritos, está o verso que constitui o F *936. O amigo então pede que Menipo pare de representar tragédias, $\pi \alpha \tilde{v} \sigma \alpha 1 \tau \rho \rho \gamma \omega \delta \tilde{\omega} v$ (1.17), e de recitar versos, $\dot{\rho} \alpha \psi \omega \delta \varepsilon \tilde{v} v$ (1.23-4). Menipo explica que declamou os versos porque estava na companhia de Eurípides e de Homero (25-6). Os versos do Héracles são enunciados pelo herói ao entrar em cena; Menipo recorreu a esses versos para anunciar sua chegada, logo no início do diálogo, e aos versos da Hécuba, enunciados pelo espectro de Polidoro no prólogo da tragédia, para dizer que viera do mundo dos mortos. É provável, portanto, que Luciano tenha parodiado uma fala de Héracles no drama de onde saiu o $\mathrm{F} * 936$, respondendo talvez a uma pergunta dos sátiros ou de Sileno ao vê-lo voltar do Hades carregando Cérbero (F 379a-380; F *863). Outras atribuições: Piritoo (ver comentários da próxima seção).

\section{0 fragmento trag. adesp. $658^{22}$}

Pirítoo, filho de Íxion, rei dos lápitas e grande amigo do herói ateniense Teseu, almejava raptar Perséfone, a sombria e bela rainha do mundo subterrâneo. Os dois amigos desceram impetuosamente ao Hades mas foram 'enganados' ( $\dot{\varepsilon} \xi \alpha \pi \alpha \tau \tilde{\alpha} \tau \alpha \iota)$ pelo deus e ficaram presos nas rochas onde estavam sentados (Apollod. Epit. 1.24); ${ }^{23}$ posteriormente, Teseu foi salvo por Héracles durante seu $12^{\circ}$ Trabalho, mas Pirítoo teve que ficar. ${ }^{24} \mathrm{~A}$ história remonta, provavelmente, a um relevo de bronze criado por volta de 560 a.C. (Olímpia B2198), ao poema Mínias (F 1 e 7) e à Heracleia de Paniassis (F 17), não necessariamente nessa ordem. No Héracles, Eurípides menciona várias vezes o salvamento de Teseu (618-9, 1169-70, 1221-2, 1235-6, 1336-7); e, de acordo com a hipótese

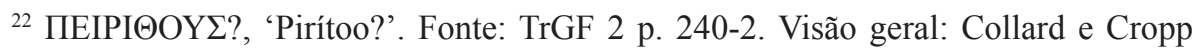
(2008, v. 2, p. 638-9), Martín (2015, p. 621-6).

${ }^{23}$ Mais informações em Ribeiro Jr. (2011, p. 29 n. 1; 105; 197); para sinopse do Piritoo de Crítias/Eurípides, ver p. 334-5.

${ }^{24}$ Teseu e Pirítoo são mencionados da Odisseia (11.630-1), mas trata-se aparentemente de interpolação tardia. 
atribuída ao Pirítoo de Crítias/Eurípides, que pode ser tanto tragédia quanto drama satírico, Teseu e Pirítoo são salvos por Héracles depois que ele domina Cérbero.

A passagem registrada em dois papiros fragmentários, um conservado em Colônia e outro em Florença, se refere indubitavelmente a esse mito. Eles foram editados separadamente em 1967 e em 1968, mas Carlini percebeu, em 2012, que pertenciam ao mesmo rolo de papiro (MARTÍN, 2015, p. 624):

a)

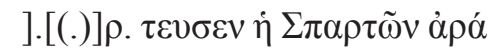

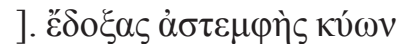

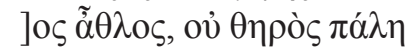

$\varepsilon] \lambda \theta \varepsilon \tilde{\varepsilon} v \tilde{\alpha} \theta[\lambda] \mathrm{o} \varsigma \dot{\alpha} \lambda \kappa \iota \mu \omega ́ \tau \alpha \tau[\mathrm{o} \varsigma$.

] $\dot{\xi} \xi \alpha v \alpha \lambda \omega ́ \sigma \omega{ }^{\prime} \sigma$ ' $\varepsilon \pi[$

$\theta] y \mu$ ò $\varepsilon \hat{\tau} \tau 0 \lambda \mu$. . [

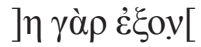

].( . )[ ].[.] $\alpha \gamma \eta[$

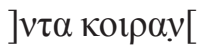

$\pi] \rho о \sigma \delta о \kappa \tilde{\omega} \nu[$

]ov ỏ $\lambda \lambda v[$

]$\lambda .[$

12

b) 25

].v $\sigma \varepsilon \chi \tilde{\omega} \rho \varsigma{ }^{\circ} \mathrm{H} \rho \alpha \kappa \lambda \varepsilon \tilde{\imath} \mu{ }^{\prime} \gamma \alpha$



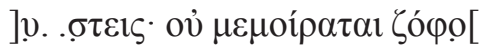



$\dot{\alpha}] \gamma \omega \gamma o ̀ \varsigma \tau \tilde{\omega} v \dot{\alpha} v 0 \sigma \tau \eta \dot{\tau} \tau \omega v$ ö $\rho \omega v$.

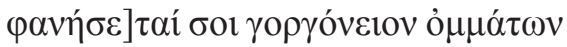

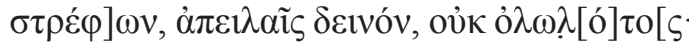

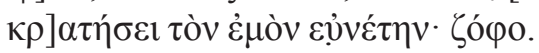

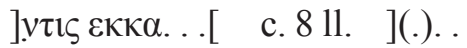



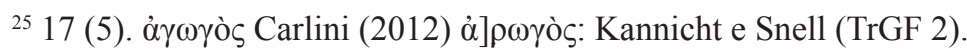


] $\tau \alpha$ vest. 15 fere $11 .[$

$$
] . . .[
$$

a)

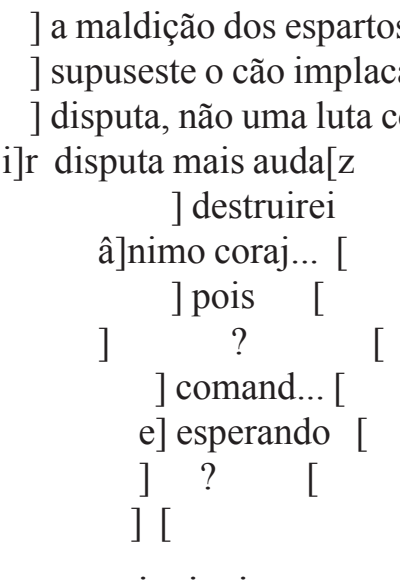

b)

] (para) ti uma terra juntamente com Héracles ]solo (?) observar como as filhas

] não está atribuída a escuridão ...

] herói; ele também irá ao mundo inferior

] guia das fronteiras de onde ninguém volta; revela]rá a ti a cabeça da górgona com seus olhos retorc] endo, assustado pelas ameaças (de quem) não pode ser morto; ] subjugará meu esposo: a escuridão.

F trag. adesp. 658a-b = P. Köhn 2 inv. 263 (a) + P. Flor. (PSI) inv. 3021 (b), saec. II d.C., com várias lacunas. a) As 5 primeiras linhas parecem uma esticomitía (KANNICHT; SNELL, TrGF 2 ad loc.), e 
um dos interlocutores deve ser o próprio Héracles; aparentemente, a

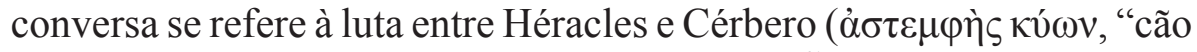
implacável") e talvez a uma tarefa ou disputa ( $\tilde{\alpha} \theta \lambda \circ \varsigma)$ adicional, ainda


e Pirítoo? Mas não há relação específica entre os espartos, associados a Cadmo, e ao mito da fundação de Tebas (Stesich. F 195; Pherec. F 22; Pind. Pyth. 9.82-3, schol. ${ }^{\mathrm{A}}$ Il. 2.494), e os elementos conhecidos do $12^{\circ}$ Trabalho de Héracles, a não ser que se trate de alguma alusão às primeiras façanhas do herói, que ocorreram nessa pólis. b) 'A $\gamma \omega \gamma$ ò, , 'condutor',


n. 25, supra): é uma provável alusão a Héracles, nomeado na linha 13, que iria conduzir Cérbero, Teseu e talvez Pirítoo para fora do Hades. Em Hécuba 534-6, Neoptólemo invocou Aquiles, seu falecido pai, e

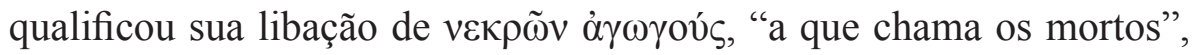
i.e., capaz de guiar as almas até o local do sacrifício de Polixena (cf.

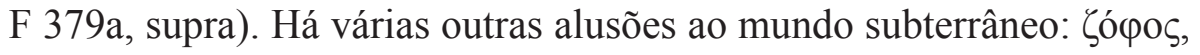

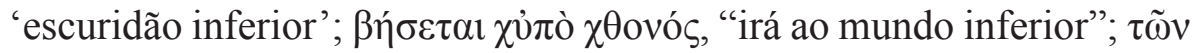

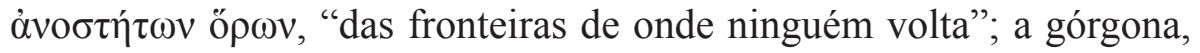
mais especificamente Medusa, encontrava-se no Hades (Od. 633-5) e, segundo [Apolodoro] (Bibl. 2.5.12), ao vê-la Héracles puxou a espada; e as "filhas" eram, provavelmente, as Erínias (COLLARD; CROPP, 2008, v. 2, p. 629, n. 4; MARTÍN, 2015, p. 624), que também se encontravam no Hades (Il. 19.259-60). Quem enuncia os versos é, provavelmente, Perséfone, que talvez preveja a salvação de Teseu (e de Pirítoo?) por

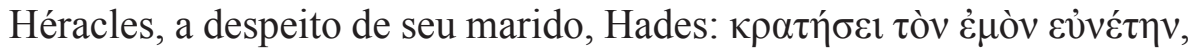
"subjugará meu esposo".

Não há como determinar se as passagens do F trag. adesp. 658.a vêm antes ou depois das passagens do 658.b; mas em Eurípides e em poetas posteriores, pelo menos, o relato atribuído a Perséfone condiz com a estrutura habitual do prólogo. Consequentemente, os versos do fragmento b) talvez devam ser colocados antes dos versos do fragmento a).

Kannicht e Snell (TrGF 2 ad loc.) antepuseram o título


anônimo do século IV a.C. Outras atribuições e seus principais defensores 
(COLLARD; CROPP, 2008, v. 2, p. 638-9; MARTÍN, 2015, p. 624-6): Pirítoo, tragédia de Crítias ou de Eurípides, ${ }^{26}$ datada do século V a.C.; Euristeu, drama satírico de Eurípides (Dana Sutton); Sátiros no Tênaro, drama satírico de Sófocles (Oliver Taplin); e uma improvável segunda versão do Héracles de Eurípides, conhecida exclusivamente pelos dois fragmentos acima (Wolfgang Luppe). Assim como Martín (2015, p. 626), inclino-me a concordar com a atribuição do $\mathrm{F}$ trag. adesp. 658 ao poeta anônimo do século IV a.C., mas decidi incluir os dois fragmentos neste estudo devido à possibilidade de o Euristeu euripidiano ter influenciado, de algum modo, o autor deste Piritoo.

\section{Reconstruindo o Euristeu de Eurípides}

Hipótese e cenário: na falta de testemunhos e de hipótese, o argumento precisa ser deduzido do título e das informações contidas nos fragmentos 371,379 e 380 , que apontam para o $12^{\circ}$ Trabalho de Héracles. O cenário mais provável é o palácio de Euristeu em Argos (ou Micenas), pois seria difícil justificar a presença do rei em outro ambiente. No mito, Héracles procura Euristeu para receber as tarefas e, posteriormente, prestar contas.

Personagens do drama: deduzidos a partir dos fragmentos conhecidos. Não há dúvidas quanto à presença de Euristeu (título), Héracles (F 371), Sileno (F 372) e os sátiros, e estes tanto pelo caráter satírico do drama quanto pelo F 375 . Van Looy (2002, p. 135) mencionou, sem justificativa específica, a possibilidade de Copreu, o arauto de Euristeu, ${ }^{27}$ ser um dos personagens, e Teseu pode ter também aparecido brevemente (COLLARD; CROPP, 2008, v. 1, p. 404), perto do fim do drama (F 377). A rigor, nem Teseu e nem Copreu são essenciais para a ação dramática.

\footnotetext{
${ }^{26}$ Não há consenso entre os especialistas sobre o autor; ver sumário da discussão em Collard e Cropp (2008, v. 2, p. 630-5).

${ }^{27} \mathrm{Na}$ Ilíada (15.638-40), Copreu é apenas o mensageiro que passava as ordens de Euristeu a Héracles; na tragédia Heráclidas, ele é o detestável arauto de Euristeu.
} 
Data: indeterminada. Se o F 379a faz referência à Alceste, certamente o Euristeu é posterior a 438 a.C. Pechstein (1998, p. 145) especulou, com base em paralelos com o Héracles, que Euristeu pertence à última década da produção de Eurípides, 415-406 a.C. Pechstein e Krumeich (1999, p. 430) propuseram o mesmo ano do Héracles, c. 415 a.C.

Alocação dos fragmentos: nenhum fragmento conhecido tem mais do que três versos completos; juntando tudo, só dispomos de uma vintena, mais palavras e frases soltas. Prólogo, párodo, episódios, estásimos e êxodo: a posição de cada fragmento na estrutura do drama, com exceção (talvez) do F 371, é puramente conjetural. O coro de sátiros usualmente entra em cena no párodo, mas não dispomos de dados suficientes dos dramas satíricos conhecidos para determinar se isso é obrigatório.

Os principais elementos da tradição mítica sobre a descida de Héracles ao Hades estavam já consolidados na época de Eurípides, a julgar pelos testemunhos literários e iconográficos disponíveis. O mito com certeza inspirou o Euristeu, a julgar pelo título e pelos fragmentos 371, 379a e 380, que deixam pouca margem a dúvidas. A presença de Euristeu e de Héracles (título, F 371), assim como a dos sátiros (ver contexto dos F 373 e 380), é certa; a de Sileno está confirmada, creio eu, pelo F 372. O tema básico que melhor associa mito e personagens é o do herói errante que derrota o ogro e salva todos, inclusive ele mesmo, de seu domínio (ver O'Sullivan e Collard, 2013, p. 30; Collard e Cropp, 2008, v. 1, p. 404); nesse cenário, Euristeu seria um ogro opressor, mas não monstruoso, a exemplo de Busíris, Círon e Sileu, personagens de outros dramas satíricos euripidianos com o mesmo tema.

A eventual participação de Teseu é bem mais difícil de justificar. Van Looy (2012, p. 135-6) não coloca o herói ateniense na sua lista de personagens e atribui a Héracles a enunciação do fragmento F 377, que menciona filhos bastardos, talvez em forma de lamento. A rigor, Héracles era filho bastardo de Alcmena, casada com Anfitrião quando foi enganada e seduzida por Zeus (Il. 14.323-4, Od. 11.266-8, Hes. Cat. F 139; Héracles 1-3 e 339-41). ${ }^{28}$ Ao contrário da tradição mítica, em

${ }^{28}$ Ver Ribeiro Jr. (2011, p. 109-11). 
Eurípides a descendência de Teseu está bem definida: ${ }^{29}$ ele é filho do ateniense Egeu (e.g. Hipólito B 1283, 1431; Suplicantes 647-8), que se casara legalmente com Etra (Suplicantes 4-7); também é filho de Posídon (Hipólito B 887-90 e 1169-70) e se tornou rei de Atenas após Egeu (Héracles 1178, Suplicantes 113-4). Pechstein (1998, p. 158-60), Collard e Cropp (2008, v. 1, p. 404) e O'Sullivan e Collard (2013, p. 392) acreditam que o fragmento pode refletir a presença de Teseu no drama satírico, mas me parece suposição grande demais para evidência tão pequena, tão tênue; Héracles ou Sileno podem ter apenas se referido a ele (COLLARD; CROPP, 2008, v. 1, p. 404; O'SULLIVAN; COLLARD, 2013, p. 392 e 397), uma vez que a libertação de Teseu do jugo de Hades faz parte do mito do $12^{\circ}$ Trabalho de Héracles.

O F 372 levou Seaford (1984, p. 36) a imaginar Cérbero representado por algum tipo de construto que se movia e falava. A esse respeito, Collard e Cropp (2008, v. 1, p. 404) e O'Sullivan e Collard (2013, p. 393) fizeram suposição muito interessante: "F 372 pode se referir até mesmo a um cão teatral gigante, talvez dois homens dentro de uma espécie de modelo ou manequim, como um cavalo de pantomima". ${ }^{30}$ É realmente bastante provável a presença de alguma representação teatral de Cérbero que, além de divertir a audiência, deve ter sido o agente do castigo do ogro. No mito e no drama satírico, o ogro sempre recebe alguma punição; em Eurípides, há três casos de morte (Busíris, Círon e Sileu) e um caso de cegamento (Ciclope), que correspondem à tradição mítica na qual o poeta se inspirou. Euristeu, no mito, não morre às mãos de Héracles, mas leva um susto enorme ao se deparar com Cérbero (seção 1, supra) e, talvez, tenha sido apenas esse o castigo que recebe no Euristeu.

Além do ogro opressor derrotado, Eurípides pode ter também recorrido ao Héracles glutão e beberrão da Alceste e de outros dramas satíricos, possibilidade sugerida pelo teor dos fragmentos 378-9, que contêm alusões a comida e a bebida. Esses excessos, porém, fazem

\footnotetext{
${ }^{29}$ As conflitantes tradições sobre o nascimento de Teseu foram resumidas por Gantz (1993, p. 248-9).

30 "F 372 may even point to a giant theatrical dog, perhaps two men inside a kind $f$ 'working model' or mock-up like a pantomime".
} 
parte do comportamento habitual dos sátiros, e os dois fragmentos podem ser apenas referências a ele. Tanto Héracles quanto os sátiros são constantemente associados, nos dramas satíricos, a grandes quantidades de bebida, mas não há nenhuma indicação quanto ao contexto específico deste fragmento.

Temos, no F 373, evidência da usual fanfarronice dos sátiros (O'SULLIVAN; COLLARD, 2013, p. 393 e 395) ou de Sileno (PECHSTEIN, 1998, p. 173; COLLARD; CROPP, 2008, v. 1, p. 407, n. 1), talvez referente à morte da hidra de Lerna, que tinha várias cabeças; e Steffen (1971) efetivamente atribui a declamação deste fragmento a Sileno. Na tragédia Héracles, os principais feitos do herói, notadamente seus "doze trabalhos" (348-435), são devidamente rememorados pelo coro, e é plausível que, no Euristeu, as façanhas anteriores sejam mencionadas em algum momento do drama (VAN LOOY, 2002, p. 136). De acordo com as fontes antigas (e.g. Hes. Theog. 313-8), Héracles recebeu a ajuda de seu sobrinho Iolau para conquistar a hidra e, provavelmente, Sileno conta que foram ele e os sátiros que participaram da luta contra o monstro. No Ciclope (5-9), ele se jacta de ter participado, com Dioniso, da derrota dos gigantes e, no Rastejadores de Sófocles (F 314.153-60), gaba-se da própria coragem. A imaterial "coragem" de Sileno e dos sátiros, nesse fragmento, é reforçada pela covardia demonstrada no F 372.

É bem possível que Sileno apresente o prólogo, que os sátiros entrem a seguir (párodo), que a chegada de Héracles ocorra logo depois, no primeiro episódio, e que Euristeu tenha entrado em cena somente depois de Héracles; recebida a tarefa, Héracles sai de cena, rumo ao mundo subterrâneo e, ao voltar, descreve suas aventuras. Essas conjeturas se baseiam na sequência de cenas do Ciclope, nosso principal modelo para os dramas satíricos baseados no tema do ogro: Odisseu sai do antro do ciclope para relatar a devoração de seus companheiros e, posteriormente, o cegamento do monstro.

No prólogo, Sileno provavelmente conta como ele e os sátiros foram escravizados e qual é sua atual situação no palácio de Euristeu; nesse caso, o F 375 poderia ser uma amostra de suas queixas sobre a condição de escravos e as tarefas não dionisíacas que ele e os filhos são 
obrigados a fazer, em contraste com seu "passado heroico" (F 373). Os F 376-8 podem ter sido declamados por Héracles (ver Van Looy, 2002, p. 136), que fala das reviravoltas de sua vida e da sujeição a homem inferior a ele, e da tarefa que veio agora receber. Resquício da entrada de Euristeu e de suas ordens para o herói ir ao Hades capturar Cérbero deve ser o F 371, uma vez que Héracles se dirige diretamente a um interlocutor ( $\pi \varepsilon ́ \mu \psi \varepsilon \iota \varsigma$ é $2^{\mathrm{a}}$ pessoa sg.), provavelmente Euristeu. Outra possibilidade é Eurípides ter criado um prólogo com dois personagens, como se vê em algumas de suas tragédias completas (e.g. Heráclidas, Electra, Ifigênia em Áulis), no drama satírico Sileu e em algumas tragédias de Sófocles (e.g. Ajax, Antígona, Édipo em Colono). ${ }^{31}$ Nesse cenário alternativo, o herói primeiro receberia a tarefa de Euristeu (F 371) e só depois entrariam Sileno e os sátiros, que pediriam então algumas explicações ao herói (F 376-8) e, em troca, explicariam sua presença ali (F 375). A segunda possibilidade me parece bem menos plausível do que a primeira.

À volta de Héracles do Hades podemos atribuir, tentativamente, os fragmentos F 372, 374, 379, 379a, 380, *863 e *936. O F 380 menciona o Tártaro e o F 379a, um condutor/conjurador de almas. Quem teria enunciado o fragmento? João de Sardes, ${ }^{32}$ nos comentários sobre a refutação de argumentos nos $\pi \rho 0 \gamma v \mu v \alpha ́ \sigma \mu \alpha \tau \alpha$ (Exercícios preparatórios)

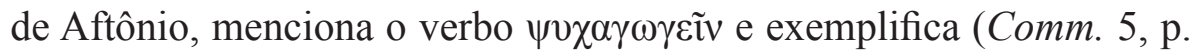


no Euristeu, na presença de Héracles”. Acredito, portanto, que Sileno ou os sátiros estavam falando com Héracles ou falando dele, ao avistá-lo em companhia de entes que pareciam almas saídas do Hades... Cérbero, com certeza, veio com ele e, possivelmente, Teseu também (ver O'Sullivan e Collard, 2013, p. 392). Suponho que o F*863 também poderia ser colocado aqui. Na mesma linha de antigo comentário de Wagner (1844, p. 190), Goins (1989, p. 402) fez uma atraente reconstrução da cena: quem fala, "provavelmente Sileno ou um dos sátiros, vê um homem,

\footnotetext{
${ }^{31}$ Sobre prólogos euripidianos com dois personagens, ver Michelini (p. 143, n. 43 e ref.); Geach (2016, p. 44-60).

32 Professor de retórica do século IX, denominado "exegeta de Sardes" por eruditos posteriores (MACDOUGALL, 2017).
} 
Héracles, a certa distância e carregando uma fera, Cérbero, que desafia descrições; é uma criatura aterrorizante e curiosa, que se parece um pouco com um javali ou um lince disforme". ${ }^{33}$ Os sátiros fazem perguntas, e uma das respostas de Héracles pode ser o conteúdo do F*963, "eu ainda respirava quando Hades me recebeu". E os sátiros naturalmente se assustam ao se ver diante do que Héracles trouxe do Hades, a "estátua de Dédalo" (F 372). O curioso F 374, que menciona vi $\pi \dot{\pi} \pi$, 'olhos roxos', 'contusões', pode também ser incluído nessa etapa do drama satírico. Só não há como dizer de quem seriam os olhos roxos mencionados... de Héracles, após o encontro com Cérbero, ou dos sátiros, rememorando lutas passadas com um esquifo cheio de vinho (F 379)? Naturalmente, esse fragmento também pode ser incluído entre as gabolices de Sileno e dos sátiros um pouco antes, no prólogo, ou pouco depois, talvez nas proximidades do $\mathrm{F} 373$.

Se o fragmento do Piritoo do século IV a.C. (trag. adesp. 658) foi inspirado de algum modo pelo Euristeu, provavelmente o anônimo autor seguiu partes do relato do herói sobre suas aventuras no mundo mediterrâneo. A parte $\mathrm{b}$ do fragmento (= PSI inv. 3021) aparentemente descreve o encontro mais ou menos amigável entre Héracles e Perséfone, e a parte a (=P. Köhn 2) menciona a luta com Cérbero e uma outra tarefa, provavelmente a libertação de Teseu.

Desse ponto em diante não há pistas, a não ser talvez a tradição do susto que Euristeu levou ao ser apresentado a Cérbero, e o F 378, que poderíamos incluir aqui e não no primeiro episódio. Kannicht (TrGF 5.1 p. 419), Collard e Cropp (2008, v. 1, p. 404) e O'Sullivan e Collard (2013, p. 393) lembram o pavor de Euristeu e seu refúgio no interior de um grande vaso, ilustrado pelos documentos iconográficos mencionados supra (seção 1), mas uma versão teatral da cena, mais digna de comédias do que de dramas satíricos, teria sido um tanto problemática com os recursos disponíveis na época de Eurípides. É mais plausível imaginar, por exemplo, Euristeu entrar em cena logo depois da volta de Héracles e

\footnotetext{
33 " The speaker, probably Silenus or one of the satyrs, sees a man, Heracles, at a distance carrying a beast, Cerberus, that defies description. It is a terrifying and curious creature that looks somewhat like a boar or a misshapen lynx".
} 
exigir provas do cumprimento da tarefa; nesse momento, "Cérbero" estaria atrás dos sátiros e fora de sua visão. Héracles simplesmente responde que trouxe o monstro, conforme solicitado, e, quando os sátiros se afastam, Euristeu se assusta com o que vê e sai de cena precipitadamente. E, já que estamos no fértil terreno das suposições, imaginemos ademais que, dependendo da mobilidade do manequim utilizado na produção, talvez "Cérbero" perseguisse o rei em cena, durante algum tempo, como em pantomimas circenses modernas...

Diante da fuga precipitada do ogro, Héracles provavelmente tece sarcásticos comentários sobre a disparidade entre a riqueza e os atos de Euristeu (F 378), informa que levará Cérbero de volta e anuncia que ele e os sátiros estão agora livres de seu algoz.

\section{Referências}

ADRADOS, F. R.; SOMOLINOS, J. R. (Dir.). Diccionario griegoespañol. Disponível em: <dge.cchs.csic.es>. Acesso: em 14 out. 2017.

BAILLY, A. Dictionnaire grec-français, rédigé avec le concours de Émile Egger. 26. éd. revue par Louis Séchan et Pierre Chantraine. Paris: Hachette, 1963.

BOSTOCK, R. N. A Commentary on Homer: Odyssey 11. 2007. 192 f. Thesis (PhD in Classics) - University of Exeter, Exeter, 2007.

CARLINI, A. Due frammenti di tragedia (Piritoo?) di uno stesso volumen: P.Köln 2 e PSI inv. 3021. In: BASTINIANINI, G.; LAPINI, W.; TULLI, M. (Ed.). Harmonia: scritti di filologia classica in onore di Angelo Casanova. Florencia: Firenze University Press, 2012. p. 183-194.

COLLARD, C.; CROPP, M. Euripides fragments. Cambridge, MA; London: Harvard University Press, 2008. 2 v.

GANTZ, T. Early Greek Myth. Baltimore: The Johns Hopkins University Press, 1993.

GEACH, J. The Euripidean Prologue. 2016. 64 f. Dissertation (Master in Arts) - The University of Arizona, Tucson, 2016.

GOINS, S. E. Euripides fr. 863 Nauck. Rheinisches Museum für Philologie, Köln, v. 132, n. 3-4, p. 401-403, 1989. 
GROTIUS, H. Dicta poetarum quae apud Io. Stobaeum exstant, emendata et latino carmine reddita. Paris: Buon, 1623.

GUIDA, A. Il codice viennese del Lessico di Andrea Lopadiota. Prometheus, Firenze, v. 5, n. 1, p. 1-20, 1979.

GUTHRIE, W. K. C. Os sofistas. 8. ed. Tradução de João R. Costa. Cambridge: Cambridge University Press, 1991.

KANNICHT, R. Tragicorum graecorum fragmenta. Göttingen: Vandenhoeck \& Ruprecht, 2004. v. 5.1 (pars prior)/v. 5.2 (pars posterior).

KANNICHT, R.; SNELL, B. Tragicorum graecorum fragmenta. Editio notis ad addenda et corrigenda revocantibus instructa. Göttingen: Vandenhoeck \& Ruprecht, 2007. v. 2.

MACDOUGALL, B. D. John of Sardis' Commentary on Aphthonius' Progymnasmata: Logic in Ninth-Century Byzantium. Greek, Roman, and Byzantine Studies, Durham, v. 57, n. 3, p. 721-744, 2017.

MARTÍN, P. L. Trágicos menores griegos del siglo V a.c., de Agatón a Meleto II (39-48 Snell-Kannicht): estudio filológico y literario. 2015. $981 \mathrm{f}$. Tesis (Doctorado) - Facultad de Filología, Universidad Nacional de Educación a Distancia, Madrid, 2015.

MATTHIAE, A. H. Euripidis tragoediae et fragmenta. Leipzig: Weigel, 1829. v. 9.

MICHELINI, A. N. Euripides and the Tragic Tradition. Madison: University of Wisconsin Press, 2006.

OGDEN, D. DRAKON: Dragon Myth and Serpent Cult in the Greek and Roman Worlds. Oxford: Oxford University Press, 2013.

O'SULliVAN, P.; COLLARD, C. Cyclops and Major Fragments of Greek Satyric Drama. Oxford: Oxbow, 2013.

PECHSTEIN, N. Euripides satyrographos: ein kommentar zu den Euripideischen satyrspielfragmenten. Stuttgart; Leipzig: Teubner, 1998.

PECHSTEIN, N.; KRUMEICH, R. Eurystheus. In: KRUMEICH, R; PECHSTEIN, N.; SEIDENSTICKER, B. (Ed.). Das griechische Satyrspiel. Darmstadt: Wissenschaftliche Buchgesellschaft, 1999. p. 422-30. 
REGER, G. A New Inventory from Mylasa in Karia. In: KONUK, K. (Coord.). Stephanèphoros de l'économie antique à l'Asie Mineure: Hommages à Raymond Descat. Bordeaux: Ausonius, 2012. p. 145-63.

RIBEIRO JR., W. A. Enganos, enganadores e enganados no mito e na tragédia de Eurípides. 2011, 484 f. Tese (Doutorado em Letras Clássicas) - Faculdade de Filosofia, Letras e Ciências Humanas, Universidade de São Paulo, São Paulo, 2011.

ROSCHER, W.H. (ed.). Ausführliches Lexikon der griechischen und römischen Mythologie. Leipzig: Teubner, 1884-1937. 6 v. 4 suppl.

SCHEFOLD, K.; GIULIANI, L. Gods and Heroes in Late Archaic Greek Art. Translated by Alan Griffits. Cambridge: Cambridge University Press, 1992 [1978].

SEAFORD, R. Euripides Cyclops, With Introduction and Commentary. Oxford: Clarendon Press, 1984.

STEFFEN, V. The Satyr-Dramas of Euripides. Eos, Wrocław, v. 59, p. 203-226, 1971.

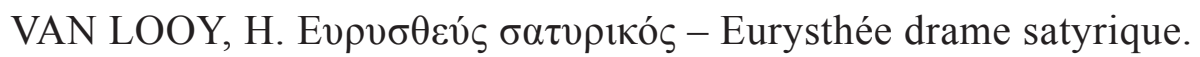
In: JOUAN, F.; VAN LOOY, H. Euripide: tragédies. De Bellérophon à Protésilas. Paris: Les Belles Lettres, 2002. tome VIII, $2^{\mathrm{e}}$ partie, p. 133141.

WAGNER, F.W. Poetarum tragicorum graecorum fragmenta: Euripidis fragmenta continens. Vratislaviae: Trewendt et Granier, 1844. v. 2.

WEIL, H. Einige bemerkunden zu den fragmenten des Euripides. Zeitschrift für die Alterthumswissenschaft, Cassel, v. 6, n. 73, p. 577-87, 1848.

Recebido em: 25 de março de 2018.

Aprovado em: 23 de abril de 2018. 